\title{
A review on metal organic frameworks (MOFs) modified membrane for remediation of water pollution
}

\author{
Qian Yuan, Guocheng Zhu ${ }^{\dagger}$ \\ College of Civil Engineering, Hunan University of Science and Technology, Xiangtan 411201, China
}

\begin{abstract}
Porous metal-organic frameworks (MOFs) have received wide attention on the potential application to separation of pollutants from contaminated water to produce clear water. Recently, the report on MOFs modified membrane in pollution separation is very interesting. The main focus is that adding MOFs onto the surface of the membrane can significantly improve its separation performance and anti-fouling ability. This review took the opportunity to give readers a preliminary and detailing understanding of the basic knowledge of the MOFs modified membrane used in remediation of water pollution.
\end{abstract}

Keywords: Membrane, Metal organic frameworks, Remediation, Water

\section{Introduction}

According to the World Health Organization (WHO), about 700 million people are still suffering from water shortages around the world, and another 500 million people are on the verge of such a dilemma, what is worse, this situation is expected to be worsen by 2025 [1]. The improvement and development of wastewater treatment technology can effectively alleviate the problem of water shortage. At present, there are many widely used waste water treatment technologies such as adsorption [2], coagulation [3], and biological treatment [4]. Although these traditional water purification technologies have been widely used, their efficiencies in treating water are becoming increasingly inadequate. For example, the cost of activated carbon adsorption in operation is high [5]. It takes a long time and occupies a large area to remove trace organic matters in water and activated sludge by coagulation [6].

With the development of modern biology and physics, membrane technology emerges. The principle of the membrane is to imitate the selective permeability of bioactive cell membrane, that is, the membrane has the property of selective passage of material on both sides [7]. Compared with the traditional wastewater treatment technology, the membrane technology can more effectively remove the color, odor, and organic matter of water, providing a green, efficient and novel method for water or wastewater treatment [8].

\subsection{Membrane Technology}

In definition, a membrane can be regarded as a selective bottleneck that can prohibit the passage of a certain substance in a complex mixture or solution under a driving force and the driving force can be generated by concentration gradient, pressure gradient or electric field [9]. Most membrane module is composed of one inlet that allows feed passes through and two outlets that are used to pass through permeate and retentate flow, respectively [10].

On the basis of pore configuration, the membrane can be classified into symmetric and asymmetric membrane [11]. Asymmetric membrane has anisotropy, that is, the chemical or physical structure of asymmetric membrane varies with the location of membrane [12]. An asymmetric membrane often consists of three layers: the top layer, the intermediate layer and the support layer. The top layer plays a crucial role in separation processes and can be modified by catalyst or other materials to improve the membrane functions [10]. The support layer supplies the asymmetric membrane with high mechanical strength and the intermediate layer combines the top layer with the support layer as a transition phase, preventing the top layer filtering into the support layer [13].

Using molecular weight cut off (MWCO), the membrane can be classified into four different processes in the membrane technology, including microfltration (MF), ultrafltration (UF), nanofltration $(\mathrm{NF})$ and reverse osmosis (RO) and they are widely used in water
This is an Open Access article distributed under the terms of the Creative Commons Attribution Non-Commercial License (http://creativecommons.org/licenses/by-nc/3.0/) which permits unrestricted non-commercial use, distribution, and reproduction in any medium, provided the original work is properly cited.

Copyright (C) 2021 Korean Society of Environmental Engineers
Received October 22, 2019 Accepted June 17, 2020

${ }^{\dagger}$ Corresponding author

Email: zhuguoc@hnust.edu.cn,zgc945ahhn@163.com

Tel: +86-731-58290269 Fax: +86-731-58290269

ORCID: 0000-0002-7423-7276 
purification [14, 15]. The materials for synthesis of membrane mainly include ceramic, polymeric and hybrid materials [16]. Polymer membrane has high selectivity and excellent mechanical strength, which is often used in water purification or desalination process [17]. Compared with polymeric membrane, ceramic membranes have the technical advantages including higher porosity, longer lifetime, better mechanical and chemical stability [18, 19].

\subsection{Membrane Fouling}

Membrane fouling is a harmful phenomenon that some substances (organic and inorganic components) adhere to the surface or inside of the membrane, which is the crucial problem for membrane technology [20]. It might markedly reduce productivity and permeate quality, leading to higher operating pressure demand, shorter membrane cleaning interval, abbreviated membrane lifespan and higher maintenance cost [21]. Membrane fouling can simply divided into inorganic fouling, biological fouling and organic fouling.

Inorganic pollution is caused by those inorganic particles attached to membrane surface or membrane pore in influent water [22]. It is also called scaling because of the pollution of chemical precipitation or crystallization of multivalent cations such as calcium, magnesium, carbonate, sulfate, and phosphate [23]. The membrane scaling will occur when the ions in the supersaturated solutions crystallize onto the membrane surface through surface crystallization and bulk crystallization [24].

Biological fouling is related to the living microorganisms in the feed water [25]. The bacteria and high-molecular-weight natural polymers as called extracellular polymeric substances secreted by multilayer of living, inactive or dead microorganisms, has a strong connection with biological fouling [26]. Biological fouling not only increases the membrane transport resistance but also biodegrades the selective layer through hydrolysis [25]. Organic fouling mainly results from deposition on the membrane surface or adsorption of organic filth such as proteins, natural organic matters, algogenic organic matter and humic substances [21]. It occurs when membrane have treated a solution contained the organic substances such as oil [27], proteins [28], and humic acid [29], which cling to the membrane surface or embed themselves inside the membrane.

The membrane fouling is affected by the membrane characteristics notably and is harmful to membrane applications [25]. Factors such as $\mathrm{pH}$, salt concentration and membrane structure will cause membrane fouling and affect the membrane technology efficiency [30] so that it is necessary to further improve the separation efficiency and application range of membrane matrix to boost the membrane performance. Therefore, one effective way to alleviate fouling is to introduce antifouling properties to membranes, which can be realized by altering surface hydrophilicity, reducing surface roughness, grafting or coating novel structured polymer and introducing new surface functionalities [31]. Scientists have extensively explored substances that can be packed within the membranes, such as mesoporous silica [32], zeolite [33], and multi-wall carbon nanotubes [34] and mental organic frameworks (MOFs) [35]. Among those materials, the MOFs have attracted extensive attention and been widely researched as a kind of filling material. For instance, Duan et al. [36] successfully gained thin-film nanocomposite (TFN) membrane with ZIF-8 as filler. The study showed that loading
$0.05 \%$ ZIF-8 on TFN film can increase the water permeability by $88 \%$ in the reverse osmosis process. Ma et al. [37] developed a novel filtration membrane with high flux, good solute rejection and excellent antifouling performance by modifying membrane with UiO-66@GO/PES, which showed high water purification performance and superb antifouling performance.

For the past few years, the improvements of membrane technology haven't stopped. As a nanoparticles introduced into membrane, the MOFs have drawn people's attention because of their large specific surface area, controllable pore diameter and other superior properties. The combination of the MOF materials as fillers with the membranes can not only improve the efficiency of membrane treatment, but also ensure the reuse of MOFs materials. In this review, various MOFs have been discussed as a filler in the membrane modification. A short introduction to membrane technology, the synthesis method and applications of the MOFs modified membrane have been reviewed.

\section{MOFs Types and Synthesis Methods}

\subsection{Fabrication of MOFs}

The MOFs, also known as coordination polymer, are a kind of organic-inorganic hybrid materials, which are different from inorganic porous materials and organic complexes. They have the inorganic porous material's rigidity and the flexible characteristic as organic material $[38,39]$. The MOFs have high specific surface area, and their maximum porosity and pore size are far greater than molecular sieve materials, of which pore size and shape can be controlled by simple methods from micro to mesoporous [40].

The MOFs are mainly utilized in the study of gas storage [41], gas/steam separation [42], selective catalysis [43], the preparation of luminescent materials [44], drug carrier materials [45] and separation [46]. Also, the MOFs have been widely employed to remove heavy metals in water phase $[47,48]$, such as lead $(\mathrm{Pb})$, arsenic (As), and mercury (Hg). The MOFs can be divided into the different categories: isoreticular metal-organic frameworks (IRMOFs), zeolitic imidazolate frameworks (ZIFs), materials of istitute lavoisierframeworks (MILs), pocket-channel frameworks (PCNs), and university of Oslo (UiO). The IRMOFs were developed by Yaghi, et al. [49]. They synthesized MOF-5, MOF-74, MOF-177, MOF-199 and IRMOF-0 at room temperature, assembled by organic ligands like various aromatic carboxylic acid with inorganic group [ $\mathrm{ZnO}]$ ${ }^{6+}$ in octahedral coordination structures [50]. The ZIFs is usually made of $\mathrm{Zn}$ or Co as metal materials with organic materials like imidazoles as ligands, which have excellent thermal and chemical stability [51]. For example, ZIF-8, remained stable under $500^{\circ} \mathrm{C}$, which was prepared by zinc nitrate hexahydrate and 2-methyl imidazole in water or N-N-Dimethyl acetamide using hydrothermal synthesis method. There is a broad development space in the fields of gas separation and catalysis for it [52]. In the preparation of MILs, different metal ions, such as chrome, iron, aluminum, vanadium and carboxylic acid ligands like succinic acid or glutaric acid for preparation, which has flexible skeleton and can achieve the channel structure change under different factor influences like temperature, pressure and adsorption materials. Therefore, in the 
specific adsorption test, the MILs has a great application value so that ML-53(Cr), ML-100(Cr), ML-101 have played an important role in gas storage and separation, catalysis, adsorption, and other fields [53-55]. The developed PCN-14 surface area reached 2176 $\mathrm{m}^{2} / \mathrm{g}$, of which performance on the methane storage was excellent [56]. The UiO takes zirconium ( $\mathrm{Zr}$ ) for metal material [57]. Among them, UiO-66 is a prominent representative in this series of research, which was synthesized by octahedral $\left[\mathrm{Zr}_{6} \mathrm{O}_{4}(\mathrm{OH})_{4}\right]$ as metal cluster with phthalic acid for organic ligand. Due to its strong coordination effect, UiO-66 has high stability so that it has huge application in the separation and the fluorescent material [58, 59].

There are many types of MOFs synthesis methods [60]. First, the hydrothermal method/solvothermal method uses stainless steel pressure reactor with teflon lining or glass tube to heat mixed raw material solution in the presence of water or organic solvents, gaining high quality single crystal through reaction under inside pressure. ML-47, ML-53, ML-101(Cr) can be synthesized by hydrothermal method, for example, MIL- 101(Cr) are synthesized by terephthalic acid and chromium nitrate hydrate in $220^{\circ} \mathrm{C}$ hydrothermal reactor [61, 62]. Second, the mechanical method makes sharp collision between raw materials' particles, and the broken particles increase the reagents contact area, effectively reducing the surface activation energy thus being beneficial to the chemical reactions for obtaining good dispersion MOFs. In general, the mechanical method does not need to add other solvents to separate the products and the solvents after synthesis, which ensures the purity of the product and is more conducive to industrialization promotion [63]. Third, microwave method uses the characteristic of raw materials that can quickly absorb electromagnetic waves, then the molecules collide. The polar molecules can achieve the required reaction temperature in a very short period of time, of which preparation is time-effective. The structure and the morphology of MOFs can be controlled by adjusting the parameters of the microwave reaction [64]. Reza et al. [65] successfully synthesized UiO-67 using microwave method, only taking 2 to $2.5 \mathrm{~h}$ at $80^{\circ} \mathrm{C}$ to $150^{\circ} \mathrm{C}$, which has a better adsorption capacity for single component $\left(\mathrm{CO}_{2}\right.$ and $\left.\mathrm{CH}_{4}\right)$. In recent years, many new preparation methods have appeared, such as electrochemical method [66], ultrasonic [67], ionothermal synthesis method [68]. The successful preparation of MOFs modified thin films provides a broader application prospects to MOFs. Compared with the solid MOFs, the MOFs modified membrane has a better application in gas separation, sensors and other fields. Due to the huge demand for the functional MOFs modified porous membrane, invesitgation on their synthesis and applications have been increasing.

\subsection{MOFs Modified Membrane}

The construction of the MOFs is close related with two areas including molecular sieve membrane synthesized by direct synthesis method or seeding growth method and coordinate polymer membranes like Langmuir-Blodgett membrane or liquid epitaxial film technology [69]. The rich research achievements in the two fields provide the possibility of the gradual combination about the MOFs' excellent performance and thin films preparation technology.

Two kinds of MOFs modified membranes can be synthesized by certain methods. The first is that the MOFs crystals in the membrane are modified, completely covered on the surface of the carrier or dispersed on the carrier. It is a kind of polycrystalline film that the MOF crystals or particles accumulate on the support surface at any orientation. The other type is the membrane surface crystal growth at a particular direction. There is an interaction between carrier surface and metal organic framework crystals. This MOFs modified membrane has a preferred orientation [70-72]. There are many preparation methods of MOFs modified membrane. Different methods and conditions can prepare different pore size, porosity and thickness of membrane. Therefore, the MOFs modified membrane can be prepared by controlling the membrane materials, carriers and preparation methods according to the actual needs. The synthesis method of MOFs modified membrane is similar to that of organometallic matrix powder, but the synthesis conditions are not membrane the same. The direct growth of metal organic skeleton crystal usually requires self-assembled monolayer (SAM) or functionalization of carrier surface by injecting crystal to promote the formation of membrane [73, 74].

\subsubsection{In situ crystallization synthesis}

In situ crystallization method, also known as direct crystallization method, refers to that under hydrothermal or solvent thermal condition that the carrier is directly in contact with the precursor sol or solution, then metal organic frame crystals produce crystal nucleus near the support body surface because of partial supersaturation. The MOFs modified film is formed by the growth crosslinking of crystal nucleus. In the process of film forming, the crystals grow on the support surface amongst the solution so that the crystal can grow on the support surface in an alternate and consecutive form [75, 76]. The advantages of in situ crystallization synthesis method are simple and convenient with strong applicability and low cost. However, due to the random nucleation on the support surface in mother liquor, in situ crystallization method requires more stringent synthesis conditions. In the process of synthesis, the direction of carrier placement will significantly affect the membrane performance. Most MOFs modified films will generate the multiple layers in the in situ crystallization method to form a thicker membrane, which has an impact on the permeability of gas separation to some extent, but in situ crystallization is still one of the most commonly used methods to synthesize the MOFs modified membrane.

The growth of MOF crystals can be controlled by proper selection of the carrier and surface modification so as to prepare dense and continuous MOFs modified films by in situ crystallization synthesis method. Hermes et al. [77] impregnated SAM containing terminal $\mathrm{COOH}$ and $\mathrm{CF}_{3}$ functional group in MOFs reaction solution to synthesize patterned MOF-5 film under conventional solvent-thermal synthesis conditions, which was only deposited on patterned $\mathrm{COOH}$ but not on the surface of $\mathrm{CF}_{3}$ functional group. The synthesized MOFs modified film was then placed in a vapor of Cp-allyl-Pd, a precursor of the organic palladium metal. As the powder particles diffused into MOF-5 by steam resulting in color changes, the MOFs modified thin film still presented porosity. The X-ray Diffraction (XRD) data showed that the MOF-5 in the film was equivalent to a conventional MOF-5 material in structure, but the selective deposition on a substrate surface expands the specific preparation and application of a MOFs modified film. In 2015, Al-Maythalony et al. [78] adopted modified porous alumina to prepare the zeo- 
lite-like metal organic framework (ZMOF) modified membrane on its substrate by solvent thermal crystallization method for the first time. The membrane had good $\mathrm{CO}_{2}$ osmotic selectivity in gas permeation separation test.

\subsubsection{Layer-by-Layer synthesis}

Under certain conditions, the carrier can be immersed in the solution of metal ion and organic precursor, respectively. One molecular layer or ion layer at a time grows on the surface of the carrier, and the metal organic framework structure can be controlled to grow in a specific crystal direction by the functional groups modified on the surface of the carrier [79]. This method for obtaining films with preferred orientation is called Layer-by-Layer (LBL) method, as the process is shown in Fig. 1. First, the carrier is immersed in metal ion precursor solution and organic precursor solution, respectively. At certain conditions, one molecular or ion layer forms in the left of the carrier and then it is immersed in the solutions again. After repeating several times, the MOFs modified membrane can be fabricated in the middle of the carrier with specific crystal direction. Shekhah et al. [80] synthesized the crystalline MOFs modified thin films by impregnating matrix in the reaction solution to form the film layer by layer. Xiang et al. [81] made the MOFs modified membrane for gas separation using the layer-by-layer method, of which strong interaction with the membrane filler matrix eliminated the interfacial gap, and the addition of MOF particles improved the selectivity of $\mathrm{H}_{2} / \mathrm{CO}_{2}$. Li et al. [82] synthesized the $\mathrm{Fe}_{3} \mathrm{O}_{4} @ \mathrm{MOFs}$ and the $\mathrm{Fe}_{3} \mathrm{O}_{4} @ \mathrm{MOF}$ / $\mathrm{GO}$ by using the layer-by-layer method, and the results showed that the presence of graphene oxide (GO) increased the drug loading of the magnetic sphere.

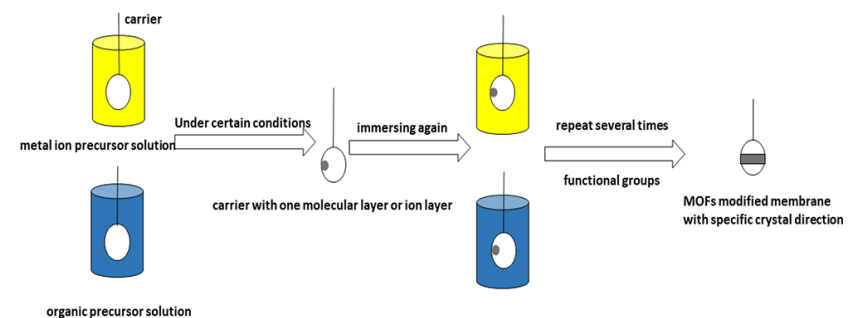

Fig. 1. Preparation of MOFs modified membrane by LBL method.

\subsubsection{Secondary growth synthesis}

Second growth method is also known as crystal seed method. This method firstly synthesizes uniform nanometer metal organic framework crystal seeds, after that forming a layer of MOFs crystal seed layer on the surface of the carrier by physical method, then the carrier is put into the synthesis solution with a certain concentration, and finally, it crystallize into the film under certain conditions [83-85]. In this method, the seed layer of metal organic framework precoating on the target support usually adopts the physical methods, in which the key step to prepare the MOFs modified film is to form thin and continuous seed layer on the carrier. The simple steps to desply the process are shown in Fig. 2. At the beginning, the MOF crystal seed layer forms on the surface of the carrier by physical method, which is immersed in MOFs modified membrane synthesis solution with a certain concentration. It can fabricate the MOFs modified membrane by crystallization at certain conditions.

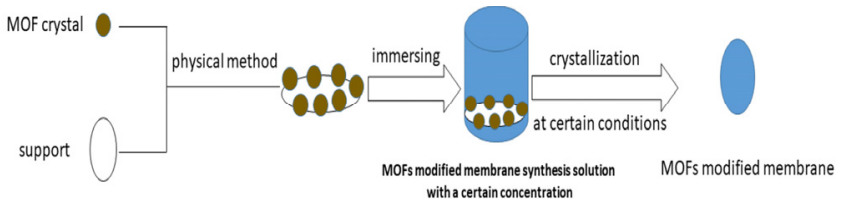

Fig. 2. Process of secondary growth method.

Du et al. [86] used nanometer ZIF-8 crystal particles as seed, induced seed growth in $\alpha-\mathrm{Al}_{2} \mathrm{O}_{3}$ ceramic tube carrier by secondary growth method, and prepared continuous ZIF-8 modified film. It was found that the ZIF-8 grains on the surface were closely connected without obvious cracks and the thickness of the film was about $18 \mu \mathrm{m}$. The separation factor of $\mathrm{H}_{2} / \mathrm{CH}_{4}$ and $\mathrm{H}_{2} / \mathrm{CO}_{2}$ was 2.56 and 5.4, respectively, which indicated that the membrane had a certain gas separation effect. Zhang et al. [87] prepared an Eu(III)-MOF modified thin films by secondary growth method, which can not only be used as a fluorescence probe for gaseous $\mathrm{SO}_{2}$, but also had a good recyclability and quick response.

The methods for seed deposition also include in situ seed reaction method and high temperature organic ligand deposition, high temperature organic ligand deposition method and others. After the seed layer deposited on the carrier, secondary hydrothermal/solvent heat treatment can be used to make the seed to form a continuous MOFs modified film [69]. Li et al. [88] obtained continuous and compact ZIF-7 modified films by crystal seed method. Yoo et al. [89] prepared dense MOF-5 crystal layers on porous $\alpha$-alumina substrates by microwave-induced thermal deposition, and then heat the MOF-5 crystal layers to grow into continuous MOF-5 modified films. Horcajada et al. [90] also prepared porous MIL-89 modified film by colloidal deposition method.

\subsubsection{Interface polymerization synthesis}

The interfacial polymerization (IP) method is adding two highly reactive monomers in two insoluble solvents and polymerize at insoluble interface to form a very thin dense layer on the porous support [31]. The nanoparticles with specific functions can be fixed on the supporting layer of the polymer separation membrane to prepare a better separation performance membrane [91-93]. As a new functional material, the MOFs can be introduced into polymer separation membrane by the interfacial polymerization. The interface polymerization method process is shown in Fig. 3. Two highly reactive monomers are placed in water phase solvent and organic phase solvent, respectively. The reaction occurs only at the interface using the MOFs as support. After washing and dehydration, the MOFs modified membrane is obtained.

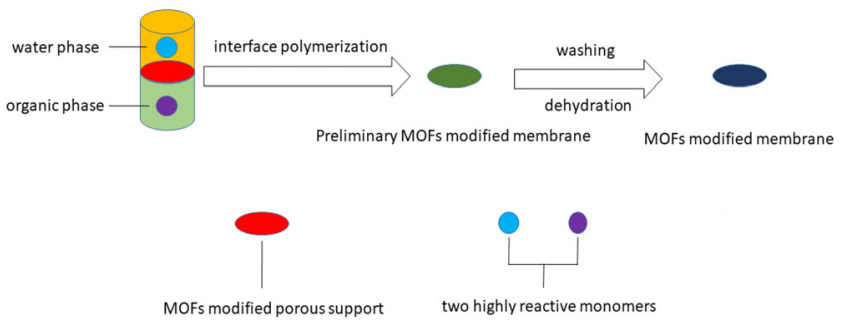

Fig. 3. Process of Interface polymerization method. 
Sorribas et al. [94] prepared nano-scale MOFs, including ZIF-8, MIL-53 (Al), $\mathrm{NH}_{2}$-MIL-53 (Al), and MIL-101 (Cr), and formed an $\mathrm{MOF}$ interfacial layer on the porous membrane of polyamide (PA) by interfacial polymerization. The interception effect of the synthesized PA-MOF modified film on styrene oligomers in methanol and tetrahydrofuran was tested. The results showed that the styrene oligomer molecules were trapped and the retention rate of PA-MOF membrane to styrene oligomer molecules in the two organic solvents was more than $92 \%$.

\subsubsection{Cohybridization synthesis}

Cohybridization method is that the matrix and the mother liquor of the modified material are mixed in a certain proportion and then transformed into a film by technical means [95]. The process is showed in Fig. 4. The matrix and mother liquor are mixed in a certain proportion and put in container with a support, which can change into MOFs modified membrane by technical means on the support. This method can not only retain the mechanical properties, chemical stability and thermal stability of the separation membrane materials, but also have the separation or other properties of modified materials, as an important technical mean of polymer separation membrane modification, which has been widely used in the production process [96-98]. Many scholars have added the multifunctional MOF material into the polymer membrane material to prepare the polymer MOF modified mixed matrix membrane (MMM) and it is prepared by several process. First, the MOF materials are added into the organic solution, dispersing evenly. After that, the polymer powder is added in it to form polymer membrane. Finally, MMM is gained by scraping and drying the composite membrane. MOF-5 [99], ZIF-8 [100], Cu-BTC [101] and other MOF materials have been reported to be added into polymer membrane materials, and have quite good applications, which enhanced the advantages and characteristics other than MMM in separation. Meera et al. [102] prepared $\mathrm{Cu}(\mathrm{BDC}) \mathrm{MMMs}$ successfully, which exhibited a $70 \%$ increase in the $\mathrm{CO}_{2} / \mathrm{CH}_{4}$ selectivity.

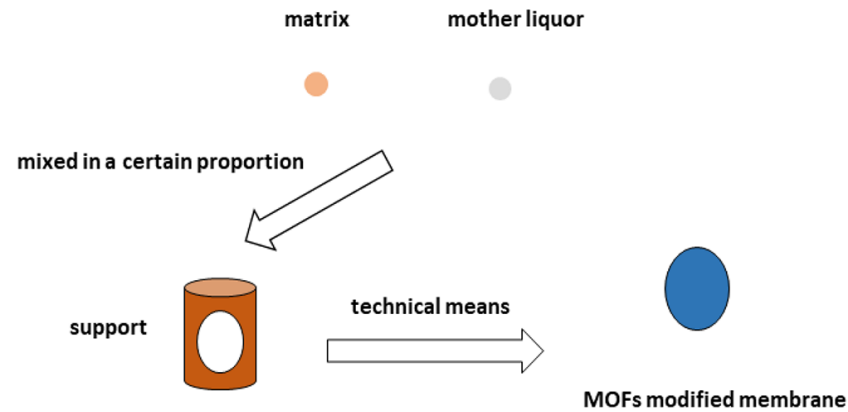

Fig. 4. Process of cohybridization method.

\subsubsection{Other methods}

Besides the in-situ crystallization and secondary growth methods mentioned above, there are also novel ways to fabricate MOFs modified films like evaporation control filler positioning method, electrochemical method, and bimetallic source method.

Goethem et al. [103] have developed a new evaporation controlled filler positioning (EFP) technique, of which main purpose is to increase the filler content in the upper layer of the film and its permeability can increase by at least $160 \%$ without affecting the salt interception rate [104]. Ameloot et al. [105] used electrochemical method to gain 2 50 $\mu \mathrm{m}$ HKUST-1 modified thin films supported by copper sheet. They sustained process in $55^{\circ} \mathrm{C}$ temperature and ventilation with $\mathrm{N}_{2}$, and the film was formed on electrochemical anodic. Yang et al. [66] successfully synthesized clear crystalline spherical MOF-5 (IL) by electrochemical method through $\pi-\pi$ bond staking effect, ionic bond, coordination bond and other effects, and their crystallization rate and thermal stability were superior to that of the solvent-thermal method.

Bimetal source method means that when the carrier and metal organic framework material have the same metal ions, the surface of the carrier will be oxidized in the reaction process, so as to provide metal ions for the carrier, which is more conducive to the formation of crystal nucleus on the carrier surface [106]. Guo et al. [107] used copper network as the carrier and activated the carrier under $100^{\circ} \mathrm{C}$, which was putted in the HKUST-1 reaction liquid at $120^{\circ} \mathrm{C}$ to prepare uniform continuous membrane modified by HKUST-1.

However, there have been many successful examples of MOFs modified membrane preparation, and there are still some challenges in the film forming property of MOF materials. For example, the instability of MOFs organic part at high temperature, the poor wettability of carrier or other problems are not conducive to the preparation of adding MOFs into films [108]. For the membrane stability, there is a lack of effective interface interaction between the MOFs and the membrane support [77, 109], so it is necessary to explore a method to enhance the interaction between the MOFs and the carrier. One of the feasible methods is to construct graphite-spun coating on the porous carrier to enhance the interface interaction between them, for instance, IRMOF-1 grown on AAO carrier was easy to fall off under ultrasonic condition, while IRMOF-1 film on AAO carrier preparation by graphite coating still had about 80\% coverage after ultrasonic 1 hour [110]. In addition, the carrier modified by alkylation reagents [111], the MOF precursor chemical [112] or polymer binders [113] can improve the dependence of the MOF crystals on the porous carrier. If the MOFs modified membrane synthesis method is not properly selected, it will lead to unstable adhesion of the MOF materials on the membrane or cause interface collapse and other problems easily.

Secondary effects in the preparation process of metal organic framework films also hinder the formation of MOFs modified film, which are caused by many complex reasons and play an important role, although it may not the dominate effect [103]. Lind et al. [114] showed that in the process of interfacial polymerization, some filler particles, once in contact with water, would immediately underwent hydration reaction and generated local heat, thus affecting the reaction kinetics of interfacial polymerization and the miscibility of solvents. In addition to the hydration reaction between filler particles and water phase, particle fragments and MOFs degradation products may also appear at the interface during IP process and the main reason is that the most common condensation polymerization reaction between chloric acid and diamine will lead to the formation of $\mathrm{HCl}$ in the IP process, which has a high degree of locality and rapidity so that the local $\mathrm{pH}$ will drop greatly, while the ZIF-8 is considered relatively stable, will degrade at a $\mathrm{pH}$ of $5[115,116]$. On this occasion, one method can be adopted 


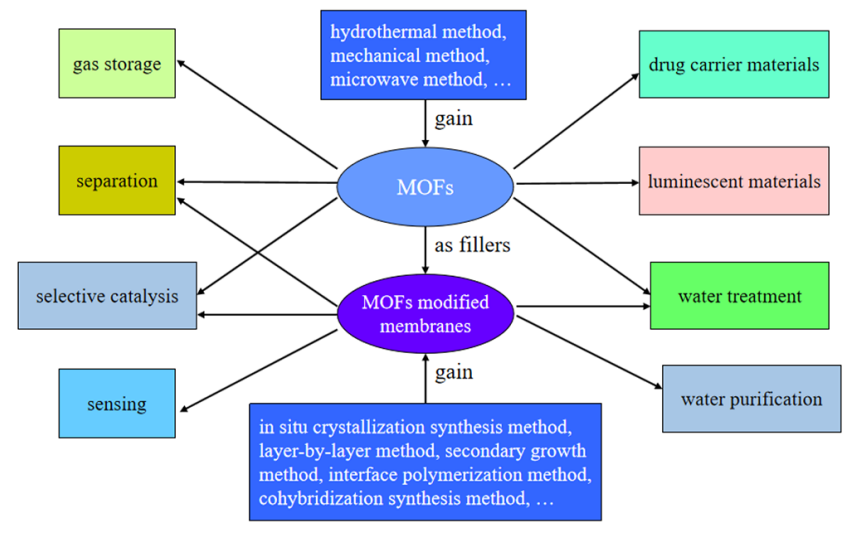

Fig. 5. An overview on application of MOFs and MOFs modified membranes.

is to add sodium hydroxide. Since sodium hydroxide is added to the aqueous solution, the function of deprotonated alcohol can increase the reactivity and the $\mathrm{P}$ reaction only forms $\mathrm{NaCl}$ as a by-product, what is more, the MOFs fillers such as ZIF-8 can remain stable under alkaline conditions [103, 117]. This article showed an overview about MOFs and MOFs modified membrane, including their synthesis methods, applications, which is shown in Fig. 5.

\section{Typical Applications in Water Treatment}

The MOFs modified membranes have been widely used in gas separation [118], catalysis [119], sensing [120], water purification [121] and other fields due to its superior performance. Ilknur et al. [122] assessed 172 different MOFs about $\mathrm{CH}_{4} / \mathrm{H}_{2}$ separation performances in membrane forms by atomically-detailed simulations aiming to find the most promising membrane materials. The results showed that most of the MOFs modified membranes exhibited high $\mathrm{CH}_{4}$ selectivity over $\mathrm{H}_{2}$ and a small number of MOF modified membranes exhibited ordinary $\mathrm{H}_{2}$ and $\mathrm{CH}_{4}$ selectivity. What was more, several MOFs were identified to exceed the upper bound established for polymeric membranes and many MOFs modified membranes showed higher gas permeabilities and selectivities. Sun et al. [123] introduced a novel metal organic framework MOF-801 nanocrystal into polyether-block-amide (PEBA) polymer to fabricate a new mixed-matrix material for $\mathrm{CO}_{2}$ separation.

Ramos et al. [124] used cylindrical cordierite as the base material and prepared MLL-101 (Cr) modified membrane by crystal seed method, which could be used as a catalyst for catalytic oxidation of tetrahydronaphthalene. Deng et al. [125] prepared PFSA/ZIF-8 composite membranes and PFSA/MIL-101 composite membranes for proton exchange membrane fuel cells. The two kinds of water stabilized MOFs grew on perforated stainless steel mesh surface modified by polydopamine (PDA) or polydopamine/Polyetherimide (PDA/PEI). Thanks to the good water absorption ability and thermal stability of the MOF layer, which is conducive to proton transfer and water management under high temperature and dry conditions, the power density of PFSA/ZIF-8 composite membrane and PFSA/MLL-101 composite membrane of proton exchange membrane fuel cell was three times higher than max power density of the commercial membrane in $60^{\circ} \mathrm{C}$. Cheng et al. [126] fabricated nanohybrid MOFs modified membrane by Fe ${ }^{\mathrm{III}}-\mathrm{HMOF}-5$ and sodium alginate (SA) matrix. The introduction of $\mathrm{Fe}^{\mathrm{III}}$ iron increased coordinatively unsaturated sites which can improve the solubility selectivity because of its preferential dissolution of water molecules over ethanol molecules and the $\mathrm{Fe}^{\mathrm{III}}$-HMOF-5 composite membrane possessed the best separation performance with the $1540 \mathrm{~g} / \mathrm{m}^{2} \mathrm{~h}$ of permeation flux when using dehydration of $90 \mathrm{wt} \%$ ethanol aqueous solution in model system, which was better than pure SA membrane and the hybrid membranes incorporating hollow MOF-5 (HMOF-5) or MOF-5. Yang et al. [127] prepared cellulose acetate (CA)/MOF@GO membranes to enhance CA membrane performance and studied its characters. The hybrid membrane exhibited higher hydrophilicity, flux recovery ratio, pure water flux and better antifouling performance because the introduced HKUST-1 can fully make use of the structure advantages of GO and prevent GO layers stacking, which showed great potential in water purification applications.

\subsection{Desalting}

Desalting is a process to produce potable water or high purity water for industrial by removing salt ions from a saline source [128] using membrane technology. It is an available option to use the MOFs modified membrane. Some efforts have been devoted to the application.

Lee et al. [129] used C300, a kind of MOF based material, as removable fillers to create porous matrix membranes, which had the best dissoluvability compared with other 2 kind of MOFs and showed higher porosity, better hydrophilicity and lower tortuosity, leading to water flux increase but a slight decrease in salt rejection. At the same time, UiO-66 particles were usually used in TFN membranes as hydrophilic fillers for forward osmosis desalination. Ma et al. [130] took this way and found that the more nanoparticles (NPs) loaded, the thicker the membrane was, with the decreased contact angle. The high NPs loading ratio decreased the flux and the salt rejection was maintained almost due to the small pore size of UiO-66, which did not allow hydrated $\mathrm{Na}^{+}$and $\mathrm{Cl}^{-}$ions to pass through.

Mil-101 (Cr) nanoparticles were prepared and embedded into the TFN membrane to improve their permeability by $\mathrm{Xu}$ et al. [131]. The results showed that the optimal addition amount of nanoparticles was 0.05 wt\%, and compared with the ordinary membrane with a flux of $2.2 \mathrm{~L} /\left(\mathrm{m}^{2} \cdot \mathrm{h} \cdot \mathrm{bar}\right)$, the water flux increased by $44 \%$, while the $\mathrm{NaCl}$ retention rate remained $99 \%$. Liu et al. [132] fabricated $2 \mu \mathrm{m}$ thickness UiO-66 modified thin film membrane by solvothermal method for desalination. The results showed that the membrane had high salt rejection toward multivalent ions, with a relatively high permeability because the UiO-66 aperture diameter was between water molecule and many hydrated ions [133].

\subsection{Removing Heavy Metal}

Some toxic metal elements are easy to harm human, which have received wide attention due to recalcitrance and persistence in the environment [134]. In recent years, the MOF membranes have 
been utilized in removing some toxic metal elements.

Yuan et al. [135] fabricated a novel ZIF-300 MOF membrane for removing heavy metal ions from wastewater. The prepared ZIF-300 membrane showed high and stable performance with 99.21\% $\mathrm{CuSO}_{4}$ rejection rate. Sana et al. [136] synthesized UiO-66- $\mathrm{NH}_{2}$ MOF through microwave heating method and incorporated it into the polyacrylonitrile (PAN) /chitosan nanofibers for removing $\mathrm{Pb}(\mathrm{II}), \mathrm{Cd}(\mathrm{II})$ and $\mathrm{Cr}(\mathrm{VI})$ ions. The results showed that the membrane had higher water flux and metal ions removal rate in aqueous solutions and its adsorption mechanism matched the Pseudo-second-order kinetic and Redlich-Peterson isotherm model, which had great potential for the removal of metal ions from aqueous solutions with filtration time less than 18h. Johnson et al. [137] embedded MOF-808 in nanofibrous membranes and studied the removal of heavy metal (lead, $\mathrm{Pb}$ ) ions by membrane adsorption/filtration. The experiment obtained S-shaped breakthrough curves about the heavy metal concentration and the filtration period. The simple model could matched the data well and revealed that the parameters involved in the model equations were correlated to the properties of mixed matrix nanofibrous membranes, including the pore size and pore size distribution, membrane thickness, fiber diameter, the adsorption rate constant, the Langmuir adsorption constant and the maximum adsorption capacity, which benefited the design of heavy metal ions removal process. Yin et al. [138] first combined MOF with ceramic membrane ultrafiltration (CUF) successfully for $\mathrm{Pb}$ (II) removal from wastewater. The results showed that the MOFs can be stored (100\%) when the membrane had an average pore size of $50 \mathrm{~nm}$. The CUF process performed best that the $\mathrm{Pb}$ (II) removal rate was $61.4 \%$ with lowest flux decline and lowest degree of membrane fouling at the conditions of $0.15 \mathrm{MPa}$ trans-membrane pressure and $4.0 \mathrm{~m} \cdot \mathrm{s}^{-1}$ cross-flow velocity in $35^{\circ} \mathrm{C}$. What was more, the membrane adsorption capacity was $1795.3 \mathrm{mg} \cdot \mathrm{g}^{-1}$ at equilibrium and the flux exhibits a recovery efficiency near $100 \%$ after 6 cycles by using $0.5 \%(w / w)$ ammonium citrate followed by $0.5 \%(\mathrm{w} / \mathrm{w}) \mathrm{HNO}_{3}$ solution and each cleaning for an hour at $18-50^{\circ} \mathrm{C}$.

\subsection{Aqueous Organic Matter Separation}

Organic matter removal is a fundamental process in sewage treatment [139] and membrane technology provides a low energy cost and high efficient way to treat it [125].

Jin et al. [140] took polyvinylidene fluoride (PVDF) nanofibrous substrate as supporter to form a high efficient MMM by embedding ZIF-8 into polydimethylsiloxane (PDMS) for phenol removal in aqueous phase membrane extraction process and it showed extraordinary high overall mass-transfer coefficient, which was much better than pristine membrane in the membrane extraction process and the high performance was kept after over $360 \mathrm{~h}$ without loss of salt rejection. Li et al. [141] incorporated hydrophilic MOF-801 crystals into chitosan (CS) matrix to fabricate MOF-801/CS MMMs for pervaporation dehydration of ethanol. MOF-801 was proved to restrain the diffusion of ethanol molecules by free volume and the lowest energy sorption sites analyses and provide additional transport pathways for water molecules, which achieved higher flux and separation factor so that the $4.8 \mathrm{wt} \% \mathrm{MOF}-801$ loading membrane could reach $1937 \mathrm{~g} / \mathrm{m}^{2} \mathrm{~h}$ the total flux of and 2156 separation factor. Mao et al. [142] prepared ZIF-8 MMMs through interfacial synthesis for ethanol permselective pervaporation and the membrane exhibited the increase in permeation flux, separation factor and good anti-tradeoff effect when used for ethanol recovery from aqueous solution and better pervaporation performance with high permeation flux and comparable separation factor in separating $5.0 \mathrm{wt} \%$ ethanol aqueous solution at $40^{\circ} \mathrm{C}$. Gao et al. [143] utilized $\mathrm{Eu}(\mathrm{BTB})\left(\mathrm{H}_{2} \mathrm{O}\right)_{2}$ 'solvent $]_{\mathrm{n}}(\mathrm{EuBTB})$, a kind of lanthanide-based two-dimensional MOFs, and sodium alginate (SA) to prepare hybrid membranes for organic solvent dehydration. Because of the strong interfacial interaction between EuBTB and SA through carboxylic groups, the hybrid membranes showed high mechanical strength and swelling resistance. At the same time, it exhibited superior permeability and ethanol dehydration selectivity, which performed best when containing 5 wt\% EuBTB with permeation flux of $1996 \mathrm{~g} / \mathrm{m}^{2} \mathrm{~h}$ and separation factor of 1160 for 90 wt\% ethanol aqueous solution at $350 \mathrm{~K}$ [129]. Neus et al. [144] prepared C-MIL-125-15- $\mathrm{NH}_{2}$ and incorporated it into mechanically stable membranes, which performed well in extraction. The hybrid material showed excellent performance in separating mixtures of bisphenol A (BPA) and 4-tert-butylphenol (4-tBP), facilitating their determination when present at low concentration levels. Alexandra et al. [145] adopted MOF-5 seed crystals to prepare MOF-5 modified membranes about $10 \mu \mathrm{m}$ thick with high quality by the secondary growth method. Although the membrane would be permanent fouled upon exposure to xylene stream so that there existed a permanent reduction in permeation flux, it was stable in organic solvent and could be used for liquid organic molecules separation based on the molecular sieving effects. Kang et al. [146] gained MMMs successfully by incorporating microporous ZIF-7 crystal particles into chitosan (CS) membrane for separating mixtures of water/ethanol at $25^{\circ} \mathrm{C}$ during pervaporation process. The ZIF-7/CS modified membranes revealed better capability in separation factor and flux than CS based membranes and MMMs. What's more, MMMs with 5 wt\% ZIF-7 showed the best separation efficiency than pristine CS membranes due to the rigidified polymer chain of MMMs [132]. Tan et al. [147] fabricated MIL-68(Al)/PVDF through mixing the MIL-68(Al) nanoparticles and PVDF casting solution for the first time, which was used to eliminate p-nitrophenol (PNP) and methylene blue (MB). In their study, all the hybrid membranes showed better adsorption capacity than pristine PVDF and the process was mainly characterized by Langmuir monolayer adsorption and chemical adsorption. The highest removal efficiency of PNP and $\mathrm{MB}$ might contribute to the coordination bonding between $-\mathrm{NO}_{2}$ of PNP with $\mathrm{Al}^{3+}$ of MIL-68(Al) and the acid-base interaction between the sulfur of $\mathrm{MB}$ and $\mathrm{Al}^{3+}$ of MIL-68(Al). D. Ragab et al. [148] modified polytetrafluoroethylene (PTFE) double layer microfiltration membrane with ZIF-8 for micropollutants removal from water, using progesterone as a model pollutant. With the incorporation of ZIF-8 onto the polymer matrix, the membrane adsorption capacity increased close to $40 \%$ and almost doubling its water permeability with a significant reduction in processing specific energy consumption, which also maintained near $95 \%$ of its original removal efficiency after three regeneration cycles using polyethylene glycol-400 [134]. 


\section{Conclusions}

It is a feasible choice to improve the performance of the membrane by coupling with the MOF materials. The properties of the membrane and the purpose for which it will be used determine the methods and types of the MOFs synthesis. It is able to enhance the membrane performance such as stability. However, the membrane still needs to improve: the instability of the organic ligands in the MOFs at high temperature as well as the poor interaction between the MOF materials and the membrane, which is likely to lead to the easily falling off of MOFs, a secondary effect and an interface collapse after the completion of the membrane modification, thus selecting an appropriate method to modify the membrane is important. The modified membrane in various fields shows an excellent performance. However, the MOFs modified membrane is still observed in laboratory scale. How to bring it to an industrial scale is still expected.

\section{Acknowledgment}

This work is financially supported by key-Area Research and Development Peogram of Guangdong Province, China (No. 2019B110205001), Natural Science Foundation of Hunan Province of China (No. 2018JJ2128), and China Postdoctoral Science Foundation (No. 2017M622578).

\section{Author Contributions}

Y.Q. (M.S. student) wrote the manuscript. Z.G. (Associate Professor) designed the review and revised the manuscript.

\section{References}

1. Organization World Health. International decade for action Water For Life, 2005-2015. Wkly. Epidemiol. Record 2005;80: 195-200.

2. Qu W, Yuan T, Yin G, Xu S, Zhang Q, Su H. Effect of properties of activated carbon on malachite green adsorption. Fuel 2019;249:45-53.

3. Ma B, Xue W, Hu C, Liu H, Qu J, Li L. Characteristics of microplastic removal via coagulation and ultrafiltration during drinking water treatment. Chem. Eng. J. 2019;359:159-167.

4. Li N, Liu Q, Zhou G, Dai M, Kong Q. Contaminant removal and microorganism response of activated sludge in sulfamethazine wastewater treatment. Int. Biodeterior. Biodegrad. 2019;143:104705.

5. TingTian. Study on Three-phase Internal Loop Biological Fluidized Bed Tecgboligy of Oily Wastewater [dissertation]. Qingdao: Ocean University of China; 2013.

6. Wang Y. Ultrafiltration System in Waterworks in Upgrading Pilot Study and Application [dissertation]. Lanzhou: Lanzhou University of Science and Technology; 2011.

7. Shaozhuang N. Membrane Separation Technology in Beverage.
China Food Ind. 2005;5:34.

8. Laîné J M, Vial D, Moulart P. Status after 10 years of operation - overview of UF technology today. Desalination 2000;131: 17-25.

9. Issaoui M, Limousy L. Low-cost ceramic membranes: Synthesis, classifications, and applications. C. R. Chim. 2019;22:175-187.

10. Thakur V K, Voicu S I. Recent advances in cellulose and chitosan based membranes for water purification: A concise review. Carbohydr. Polym. 2016;146:148-165.

11. Voicu SI, Stanciu ND, Nechifor AC, Vaireanu DI, Nechifor G. Synthesis and characterization of ionic conductive polysulfone composite membranes. Rom. J. Inf. Sci. Tech. 2009;12:410-422.

12. Goei R, Lim T. Asymmetric $\mathrm{TiO}_{2}$ hybrid photocatalytic ceramic membrane with porosity gradient: Effect of structure directing agent on the resulting membranes architecture and performances. Ceram. Int. 2014;40:6747-6757.

13. Lindqvist K, Lidén E. Preparation of alumina membranes by tape casting and dip coating. J. Eur. Ceram. Soc. 1997;17:359-366.

14. Ihsanullah, Amer A M A, Laoui T, et al. Hilal N. Fabrication and antifouling behaviour of a carbon nanotube membrane. Mater. Des. 2016;89:549-558.

15. He Z, Lyu Z, Gu Q, Zhang L, Wang J. Ceramic-based membranes for water and wastewater treatment. Colloids Surf. A 2019;578:123513.

16. Ihsanullah. Carbon nanotube membranes for water purification: Developments, challenges, and prospects for the future. Sep. Purif. Technol. 2019;209:307-337.

17. Zhang W, Zhang Y, Fan R, Lewis R. A facile $\mathrm{TiO}_{2} / \mathrm{PVDF}$ composite membrane synthesis and their application in water purification. J. Nanopart. Res. 2016;18:1-10.

18. Padaki M, Surya MR, Abdullah MS, et al. Ismail AF. Membrane technology enhancement in oil-water separation. A review. Desalination 2015;357:197-207.

19. Hofs B, Ogier J, Vries D, Beerendonk EF, Cornelissen ER. Comparison of ceramic and polymeric membrane permeability and fouling using surface water. Sep. Purif. Technol. 2011;79: 365-374

20. Mikhaylin S, Bazinet L. Fouling on ion-exchange membranes: Classification, characterization and strategies of prevention and control. Adv. Colloid Interface Sci. 2016;229:34-56.

21. Liao Y, Bokhary A, Maleki E, Liao B. A review of membrane fouling and its control in algal-related membrane processes. Bioresour. Technol. 2018;264:343-358.

22. Wang Z, Ma J, Tang CY, Kimura K, Wang Q, Han X. Membrane cleaning in membrane bioreactors: A review. J. Membr. Sci. 2014;468:276-307.

23. Shirazi S, Lin C, Chen D. Inorganic fouling of pressure-driven membrane processes - A critical review. Desalination 2010;250:236-248.

24. Warsinger D M, Swaminathan J, Guillen-Burrieza E, Arafat HA, Lienhard VJH. Scaling and fouling in membrane distillation for desalination applications: A review. Desalination 2015;356:294-313.

25. Goh PS, Lau WJ, Othman MHD, Ismail AF. Membrane fouling in desalination and its mitigation strategies. Desalination 2018;425:130-155.

26. Yu W, Yang Y, Graham N. Evaluation of ferrate as a coagulant 
aid/oxidant pretreatment for mitigating submerged ultrafiltration membrane fouling in drinking water treatment. Chem. Eng. J. 2016;298:234-242.

27. Chaabane L. Ageing of ion-exchange membranes used in an electrodialysis for food industry: SEM, EDX, and limiting current investigations. Desalin. Water Treat. 2015;56:2561-2566.

28. Ruiz B, Sistat P, Huguet P, Pourcelly G, Araya-Farias M, Bazinet L. Application of relaxation periods during electrodialysis of a casein solution: Impact on anion-exchange membrane fouling. J. Membr. Sci. 2007;287:41-50.

29. Lindstrand V, Sundström G, Jönsson A. Fouling of electrodialysis membranes by organic substances. Desalination 2000; 128:91-102.

30. Liu Z, Xu S, Li S. Membrane Fouling And Cleaning in UF And MF. Technol. Water Treat. 1997;22:3-9.

31. Jeong B, Hoek EMV, Yan Y, et al. Interfacial polymerization of thin film nanocomposites: A new concept for reverse osmosis membranes. J. Membr. Sci. 2007;294:1-7.

32. Yan W, Shi M, Wang Z, et al. Amino-modified hollow mesoporous silica nanospheres-incorporated reverse osmosis membrane with high performance. J. Membr. Sci. 2019;581:168-177.

33. Zhu M, Huang S, Gong Y, et al. Effect of flouride on preparation and pervaporation performance of $\mathrm{NaY}$ zeolite membrane for EtOH/ETBE mixture. Microporous Mesoporous Mater. 2019;282: 48-52.

34. Zhou R, Rana D, Matsuura T, Lan CQ. Effects of multi-walled carbon nanotubes (MWCNTs) and integrated MWCNTs $/ \mathrm{SiO}_{2}$ nano-additives on PVDF polymeric membranes for vacuum membrane distillation. Sep. Purif. Technol. 2019;217:154-163.

35. Lau WJ, Stephen G, Matsuura T, Emadzadeh D, J Paul C, Ismail AF. A review on polyamide thin film nanocomposite (TFN) membranes: History, applications, challenges and approaches. Water Res. 2015;80:306-324.

36. Duan J, Pan Y, Pacheco F, Litwiller E, Lai Z, Pinnau I. High-performance polyamide thin-film-nanocomposite reverse osmosis membranes containing hydrophobic zeolitic imidazolate framework-8. J. Membr. Sci. 2015;476:303-310.

37. Ma J, Guo X, Ying Y, Liu D, Zhong C. Composite ultrafiltration membrane tailored by MOF@GO with highly improved water purification performance. Chem. Eng. J. 2017;313:890-898.

38. Seoane B, Castellanos S, Dikhtiarenko A, Kapteijn F, Gascon J. Multi-scale crystal engineering of metal organic frameworks. Coord. Chem. Rev. 2016;307:147-187.

39. Li W, Zhang Y, Li Q, Zhang G. Metal-organic framework composite membranes: Synthesis and separation applications. Chem. Eng. Sci. 2015;135:232-257.

40. Elsaidi SK, Mohamed MH, Banerjee D, Thallapally PK. Flexibility in Metal-Organic Frameworks: A fundamental understanding. Coord. Chem. Rev. 2018;358:125-152.

41. Langmi HW, Ren J, North B, Mathe M, Bessarabov D. Hydrogen Storage in Metal-Organic Frameworks: A Review. Electrochim. Acta 2014;128:368-392.

42. Finsy V, Ma L, Alaerts L, Vos DED, Baron GV, Denayer JFM. Separation of $\mathrm{CO}_{2} / \mathrm{CH}_{4}$ mixtures with the MLL-53(Al) metal-organic framework. Microporous Mesoporous Mater. 2009;120: 221-227.

43. Chen YZ, Zhang R, Jiao L, Jiang HL. Metal-organic framework-derived porous materials for catalysis. Coord. Chem. Rev.
2018;362:1-23.

44. Xu X, Guo Y, Wang X, et al. Sensitive Detection of Pesticides by a Highly Luminescent Metal-organic Framework. Sens. Actuators, B 2018;260:239-245.

45. Lei Z, Yan C, Rui S, et al. Synthesis of hollow nanocages MOF-5 as drug delivery vehicle to solve the load-bearing problem of insoluble antitumor drug oleanolic acid (OA). Inorg. Chem. Commun. 2018;96:20-23.

46. Hao L, Wang K, Sun Y, Lollar C T, Li J, Zhou H C. Recent advances in gas storage and separation using metal-organic frameworks. Mater. Today 2017;2017:108-121.

47. Wen J, Fang Y, Zeng G. Progress and prospect of adsorptive removal of heavy metal ions from aqueous solution using metalorganic frameworks: a review of studies from the last decade. Chemosphere 2018;201:627-643.

48. Xiong N, Wan P, Zhu G, et al. Sb(III) removal from aqueous solution by a novel nano-modified chitosan (NMCS). Sep. Purif. Technol. 2020;236:116266.

49. Morris W, Taylor RE, Dybowski C, Yaghi OM, Garcia-Garibay MA. Framework mobility in the metal-organic framework crystal IRMOF-3: Evidence for aromatic ring and amine rotation. J. Mol. Struct. 2011;1004:94-101.

50. Tranchemontagne DJ, Hunt JR, Yaghi OM. Room temperature synthesis of metal-organic frameworks: MOF-5, MOF-74, MOF-177, MOF-199, and IRMOF-0. Tetrahedron 2008;64: 8553-8557.

51. Safaei M, Foroughi MM, Ebrahimpoor N, Jahani S, Omidi A, Khatami M. A review on metal-organic frameworks: Synthesis and applications. TrAC, Trends Anal. Chem. 2019;118:401-425.

52. Pokhrel J, Bhoria N, Anastasiou S, et al. $\mathrm{CO}_{2}$ adsorption behavior of amine-functionalized ZIF-8, graphene oxide, and ZIF-8/graphene oxide composites under dry and wet conditions. Microporous Mesoporous Mater. 2018;267:53-67.

53. Adhikari A K, Lin K S, Tu M T. Hydrogen storage capacity enhancement of MIL-53(Cr) by Pd loaded activated carbon doping. J. Taiwan Inst. Chem. Eng. 2016;63:463-472.

54. Ying M, Hui Q, Gan Y, et al. Green and time-saving synthesis of MIL-100(Cr) and its catalytic performance. Microporous Mesoporous Mater. 2019;274:70-75.

55. Thanh HTM, Phuong TTT, Hang PTL, et al. Comparative study of $\mathrm{Pb}(\mathrm{II})$ adsorption onto $\mathrm{ML}-101$ and $\mathrm{Fe}-\mathrm{ML}-101$ from aqueous solutions. J. Environ. Chem. Eng. 2018;6:4093-4102.

56. Sun H, Zhang J, Ouyang C, Ren Z, Li J. Computational evaluation of the impact of metal substitution on the $14 \mathrm{CH}_{4}$ storage in PCN-14 metal-organic frameworks. Catal. Today 2018;312: 168-173.

57. Chen S, Lin Z, Zhao Z, et al. Study on Desorption Process of n-Heptane and Methyl Cyclohexane Using UiO-66 with Hierarchical Pores. Acs. Appl. Mater. Interfaces 2018;10: 21612-21618.

58. Zhao S, Chen D, Xu H, et al. Combined effects of Ag and UiO-66 for removal of elemental mercury from flue gas. Chemosphere 2018;197:65-72.

59. Jin $\mathrm{L}, \mathrm{Xu} \mathrm{F}$, Jing $\mathrm{H}$, et al. Preconcentration on metal organic framework UiO-66 for slurry sampling hydride generation-atomic fluorescence spectrometric determination of ultratrace arsenic. Microchem. J. 2017;133:441-447. 
60. Yongning B, Nana X, Guocheng Z. Technology for the Remediation of Water Pollution: A Review on the Fabrication of Metal Organic Frameworks. Processes 2018;6:122.

61. Wang X, Jacobson AJ. Hydrothermal crystal growth and Vernier structures of the metal benzenedicarboxylates MIL-47 and MIL-53 containing guest molecules of benzenecarboxylic acid. J. Solid State Chem. 2016;236:230-235.

62. Yang LT, Qiu LG, Hu SM, Jiang X, Xie AJ, Shen YH. Rapid hydrothermal synthesis of MIL-101(Cr) metal-organic framework nanocrystals using expanded graphite as a structure-directing template. Inorg. Chem. Commun. 2013;35:265-267.

63. Ma J. Fabrication and Separation Performance of Nanoporous Materials Based Mixed Matrix Membranes [dissertation]. Beijing: Beijing University of Chemical Technology; 2017.

64. Isaeva VI, Kustov LM. Microwave activation as an alternative production of metal-organic frameworks. Russ. Chem. Bull. 2016;65:2103-2114.

65. Vakili R, Xu S, Al-Janabi N, Gorgojo P, Holmes SM, Fan X. Microwave-assisted synthesis of zirconium-based metal organic frameworks (MOFs): Optimization and gas adsorption. Micropor. Mesopor. Mater. 2018;260:45-53.

66. Yang HM, Liu X, Song XL, Yang TL, Liang ZH, Fan CM. In situ electrochemical synthesis of MOF-5 and its application in improving photocatalytic activity of BiOBr. Chin. J. Catal. 2015;25:3987-3994

67. Abuzalat O, Wong D, Elsayed M, Park S, Kim S. Sonochemical Fabrication of $\mathrm{Cu}$ (II) and $\mathrm{Zn}$ (II) Metal-Organic Framework Films on Metal Substrates. Ultrason. Sonochem. 2018;45:180-188.

68. Olorunyomi JF, Chan KY, Gao L, Voskanyan A, Li CYV. Direct synthesis of anion-exchange polymer threaded in a metal organic framework through in situ polymerization of an ionic liquid. Micropor Mesopor. Mater. 2017;259:255-263.

69. Zhang F, Sun FX, Zhu GS. Preparation and application of metal-organic framework films. Sci. Sin. 2013;43:1748-1760.

70. Rob A, Elena G, Hiroshi UI, et al. Direct patterning of oriented metal-organic framework crystals via control over crystallization kinetics in clear precursor solutions. Adv. Mater. 2010;22:2685-2688

71. Tu L, Zheng XL, Lee HL. A Biomimetic Nose by Microcrystals and Oriented Films of Luminescent Porous Metal-Organic Frameworks. Cryst. Growth Des. 2011;11:4146-4154.

72. Katsuhiko K, Rie H, Osami S, Mamoru Y, Yasuyuki A, Hiroshi K. Construction of highly oriented crystalline surface coordination polymers composed of copper dithiooxamide complexes. J. Am. Chem. Soc. 2008;130:15778-15779.

73. Allara DL, Nuzzo RG. Spontaneously Organized Molecular Assemblies. 1. Formation, Dynamics, and Physical Properties of n-Alkanoic Acids Adsorbed from Solution on an Oxidized Aluminum Surface. Langmuir 1985;1:45-52.

74. Bo L, Mingyan M, Denise Z, et al. Chemistry of SURMOFs: layer-selective installation of functional groups and post-synthetic covalent modification probed by fluorescence microscopy. J. Am. Chem. Soc. 2011;133:1734-1737.

75. Shah M, Kwon HT, Tran V, Sachdeva S, Jeong HK. One step in situ synthesis of supported zeolitic imidazolate framework ZIF-8 membranes: Role of sodium formate. Microporous Mesoporous Mater. 2013;165:63-69.
76. Li Z, Zhang M, Xue W, Qiu L. In situ Preparation of Metal organic Frameworl $\left[\mathrm{Zn}(\mathrm{BDC})\left(\mathrm{H}_{2} \mathrm{O}\right)_{2}\right]_{\mathrm{n}}$ Films and Reversible Detection of Nitrobenzenes. Chin. J. Lumin. 2011;32:514-518.

77. Stephan H, Felicitas SD, Rolf C, Christof WL, Fischer RA. Selective nucleation and growth of metal-organic open framework thin films on patterned $\mathrm{COOH} / \mathrm{CF}_{3}$-terminated self-assembled monolayers on $\mathrm{Au}(\mathrm{III})$. J. Am. Chem. Soc. 2005;127: 13744-13745.

78. Al-Maythalony BA, Osama S, Raja S, Youssef B, Ingo P, Mohamed E. Quest for anionic MOF membranes: continuous sod-ZMOF membrane with $\mathrm{CO}_{2}$ adsorption-driven selectivity. J. Am. Chem. Soc. 2015;137:1754-1757.

79. Lee D, Li Q, Kim H, Lee K. Preparation of Ni-MOF-74 membrane for $\mathrm{CO}_{2}$ separation by layer-by-layer seeding technique. Micropor. Mesopor. Mater. 2012;163:169-177.

80. Osama S, Hui W, Stefan K, et al. Step-by-step route for the synthesis of metal-organic frameworks. J. Am. Chem. Soc. 2007;129:15118-15119.

81. Xiang F, Marti AM, Hopkinson DP. Layer-by-layer assembled polymer/MOF membrane for $\mathrm{H}_{2} / \mathrm{CO}_{2}$ separation. J. Membr. Sci. 2018;556:146-153.

82. Li L, Sun KK, Fan L, Hong W, Xu ZS, Liu L. Layer by layer assembly synthesis of $\mathrm{Fe}_{3} \mathrm{O}_{4} @ \mathrm{MOFs} / \mathrm{GO}$ core-shell nanoparticles. Mater. Lett. 2014;126:197-201.

83. Zou X, Zhang F, Thomas S, Zhu G, Valtchev V, Mintova S. $\mathrm{Co}_{3}(\mathrm{HCOO})_{6}$ Microporous Metal\&ndash;Organic Framework Membrane for Separation of $\mathrm{CO}_{2} / \mathrm{CH}_{4}$ Mixtures. Chem. Eur. J. 2011;17:12076-12083.

84. Zhou S, Zou X, Sun F, et al. Challenging fabrication of hollow ceramic fiber supported $\mathrm{Cu}_{3}(\mathrm{BTC})_{2}$ membrane for hydrogen separation. J. Mater. Chem. 2012;22:10322-10328.

85. Zhao Z, Zhong LI, Yslin J. Secondary growth synthesis of MOF-5 membranes by dip-coating nano-sized MOF-5 seeds. CIESC J. 2011;62:507-514.

86. Du S, Liu Y, Kong L, Zhang J, Liu H. Seeded Secondary Growth Synthesis of ZIF-8 Membranes Supported on $\alpha-\mathrm{Al}_{2} \mathrm{O}_{3}$ Ceramic Tubes. J. Inorg. Mater. 2012;27:1105-1111.

87. Zhang J, Xia T, Zhao D, Cui Y, Yang Y, Qian G. In situ secondary growth of Eu(III)-organic framework film for fluorescence sensing of sulfur dioxide. Sens. Actuators, B 2018;260:63-69.

88. Li Y, Liang F, Bux H, Yang W, Caro J. Zeolitic imidazolate framework ZIF-7 based molecular sieve membrane for hydrogen separation. J. Membr. Sci. 2010;354:48-54.

89. Yoo Y, Lai Z, Jeong HK. Fabrication of MOF-5 membranes using microwave-induced rapid seeding and solvothermal secondary growth. Micropor. Mesopor. Mater. 2009;123:100-106.

90. Horcajada P, Serre C, Grosso D, et al. Colloidal Route for Preparing Optical Thin Films of Nanoporous Metal-Organic Frameworks. Adv. Mater. 2010;21:1931-1935.

91. Yin J, Zhu G, Deng B. Graphene oxide (GO) enhanced polyamide (PA) thin-film nanocomposite (TFN) membrane for water purification. Desalination 2016;379:93-101.

92. Freger V. Nanoscale Heterogeneity of Polyamide Membranes Formed by Interfacial Polymerization. Langmuir 2003;19: 4791-4797.

93. Rajesh, Ahuja T, Kumar D. Recent progress in the development of nano-structured conducting polymers/nanocomposites for 
sensor applications. Sens. Actuators B 2009;136:275-286.

94. Sara S, Patricia G, Carlos T, Joaquín C, Livingston AG. High flux thin film nanocomposite membranes based on metal-organic frameworks for organic solvent nanofiltration. J. Am. Chem. Soc. 2013;135:15201-15208.

95. Yang MC, Liu TY. The permeation performance of polyacrylonitrile/polyvinylidine fluoride blend membranes. J. Membr. Sci. 2003;226:119-130.

96. Ochoa NA, Masuelli M, Marchese J. Effect of hydrophilicity on fouling of an emulsified oil wastewater with PVDF/PMMA membranes. J. Membr. Sci. 2003;226:203-211.

97. Lin DJ, Chang CL, Lee CK, Cheng LP. Preparation and characterization of microporous PVDF/PMMA composite membranes by phase inversion in water/DMSO solutions. Eur. Polym. J. 2006;42:2407-2418.

98. Park JY, Acar MH, Akthakul A, Kuhlman W, Mayes A . Polysulfone-graft-poly (ethylene glycol) graft copolymers for surface modification of polysulfone membranes. Biomaterials 2006;27:856-865.

99. Perez EV, Jr KJB, Ferraris JP, Musselman IH. Mixed-matrix membranes containing MOF-5 for gas separations. J. Membr. Sci. 2009;328:165-173.

100. Ordoñez MJC, Balkus Jr KJ, Ferraris JP, Musselman IH. Molecular sieving realized with ZIF-8/Matrimid ${ }^{\circledR}$ mixed-matrix membranes. J. Membr. Sci. 2010;361:28-37.

101. Yeang QW, Sulong AB, Tan SH. Asymmetric membrane containing electrospun $\mathrm{Cu}-\mathrm{BTC} /$ poly(vinyl alcohol) for pervaporation dehydration of 1,4-dioxane. Sep. Purif. Technol. 2018;192:240-252.

102. Shete M, Kumar P, Bachman JE, et al. On the direct synthesis of $\mathrm{Cu}(\mathrm{BDC}) \mathrm{MOF}$ nanosheets and their performance in mixed matrix membranes. J. Membr. Sci. 2018;549:312-320.

103. Goethem C V, Verbeke R, Pfanmöller Mand, et al. The role of MOFs in Thin-Film Nanocomposite (TFN) membranes. J. Membr. Sci. 2018;563:938-948.

104. Goethem CV, Verbeke R, Hermans S, Bernstein R, Vankelecom I. Controlled Positioning of MOFs in Interfacially Polymerized Thin-Film Nanocomposites. J. Mater. Chem. A 2016;4: 16368-16376.

105. Ameloot R, Stappers L, Fransaer J, Alaerts L, Sels BF, Vos DED. Patterned Growth of MetalOrganic Framework Coatings by Electrochemical Synthesis. Chem. Mater. 2009;21: 2580-2582.

106. Feng Z, Zou X, Sun F, Hao R, Yuan J, Zhu G. Growth of preferential orientation of $\mathrm{MLL}-53(\mathrm{Al})$ film as nano-assembler. CrystEngComm 2012;14:5487-5492.

107. Hailing G, Guangshan Z, Hewitt IJ, Shilun Q. "Twin copper source" growth of metal-organic framework membrane: $\mathrm{Cu}_{3}(\mathrm{BTC})_{2}$ with high permeability and selectivity for recycling $\mathrm{H}_{2}$. J. Am. Chem. Soc. 2009;131:1646-1647.

108. Mitzi DB, Prikas MT, Chondroudis K. Thin-Film Deposition of Organic-Inorganic Hybrid Materials. Chem. Mater. 2001;13:3283-3298.

109. Guerrero VV, Yoo Y, Mccarthy MC, Jeong HK. HKUST-1 membranes on porous supports using secondary growth. J. Mater. Chem. 2010;20:3938-3943.

110. Yoo Y, Jeong HK. Rapid fabrication of metal organic framework thin films using microwave-induced thermal deposition. Chem. Commun. 2008;2008:2441-2443.

111. Aisheng H, Wei D, Jürgen C. Steam-stable zeolitic imidazolate framework ZIF-90 membrane with hydrogen selectivity through covalent functionalization. J. Am. Chem. Soc. 2010;132:15562-15564.

112. Li Y, Liang F, Bux H, Feldhoff A. Molecular sieve membrane: supported metal-organic framework with high hydrogen selectivity. Angew. Chem., Int. Ed. 2010;3:548-551.

113. Mccarthy M C, Victor V G, Barnett G V, Hae-Kwon J. Synthesis of zeolitic imidazolate framework films and membranes with controlled microstructures. Langmuir 2010;26:14636-14641.

114. Lind BHJM, Subramani A, Hoek XHAE. Effect of mobile cation on zeolite-polyamide thin film nanocomposite membranes. J. Mater. Res. 2009;24:1624-1631.

115. Sun CY, Qin C, Wang XL, et al. Zeolitic Imidazolate framework-8 as efficient pH-sensitive drug delivery vehicle. Dalton Trans. 2012;41:6906.

116. Bhattacharyya S, Pang SH, Dutzer MR, Lively RP, Nair S. Interactions of $\mathrm{SO}_{2}$-Containing Acid Gases with ZIF-8: Structural Changes and Mechanistic Investigations. J. Phys. Chem. C 2016;120:27221-27229.

117. Park KS, Ni Z, Côté AP, et al. Exceptional chemical and thermal stability of zeolitic imidazolate frameworks. Proc. Natl. Acad. Sci. U. S. A. 2006;103:10186-10191.

118. Aykac OH, Ozturk B. Gas separation characteristic of mixed matrix membrane prepared by MOF-5 including different metals. Sep. Purif. Technol. 2019;211:514-521.

119. Hou X, Stanley S L, Zhao M, et al. MOF-based C-doped coupled $\mathrm{TiO}_{2} / \mathrm{ZnO}$ nanofibrous membrane with crossed network connection for enhanced photocatalytic activity. J. Alloys Compd. 2019;777:982-990.

120. Xu Y, Wen Y, Zhu W, Wu Y, Lin C, Li G. Electrospun nanofibrous mats as skeletons to produce MOF membranes for the detection of explosives. Mater. Lett. 2012;87:20-23.

121. Cheng D, Zhao L, Li N, et al. Aluminum fumarate MOF/PVDF hollow fiber membrane for enhancement of water flux and thermal efficiency in direct contact membrane distillation. J. Membr. Sci. 2019;588:117204.

122. Erucar I, Keskin S. Computational assessment of MOF membranes for $\mathrm{CH}_{4} / \mathrm{H}_{2}$ separations. J. Membr. Sci. 2016;514: 313-321.

123. Sun J, Li Q, Chen G, Duan J, Liu G, Jin W. MOF-801 incorporated PEBA mixed-matrix composite membranes for $\mathrm{CO}_{2}$ capture. Sep. Purif. Technol. 2019;217:229-239.

124. Ramos-Fernández EV, Garcia-Domingos M, Juan-Alcañiz J, Gascon J. MOFs meet monoliths: Hierarchical structuring metal organic framework catalysts. Appl. Catal., A 2011;391: 261-267.

125. Deng R, Han W, Yeung KL. Confined PFSA/MOF composite membranes in fuel cells for promoted water management and performance. Catal. Today 2019;331:12-17.

126. Cheng X, Jiang Z, Cheng X, et al. Bimetallic metal-organic frameworks nanocages as multi-functional fillers for water-selective membranes. J. Membr. Sci. 2018;545:19-28.

127. Yang S, Zou Q, Wang T, Zhang L. Effects of GO and MOF@GO on the permeation and antifouling properties of cellulose ace- 
tate ultrafiltration membrane. J. Membr. Sci. 2019;569:48-59.

128. Kadhom M, Deng B. Metal-organic frameworks (MOFs) in water filtration membranes for desalination and other applications. Appl. Mater. Today 2018;11:219-230.

129. Lee JY, She Q, Huo F, Tang CY. Metal-organic framework-based porous matrix membranes for improving mass transfer in forward osmosis membranes. J. Membr. Sci. 2015;492:392-399.

130. Ma D, Peh SB, Han G, Chen SB. Thin-Film Nanocomposite (TFN) Membranes Incorporated with Super-Hydrophilic Metal-Organic Framework (MOF) UiO-66: Toward Enhancement of Water Flux and Salt Rejection. ACS Appl. Mater. Interfaces 2017;9:7523-7534.

131. Xu Y, Gao X, Wang X, Wang Q, Ji Z. Highly and Stably Water Permeable Thin Film Nanocomposite Membranes Doped with MIL-101 (Cr) Nanoparticles for Reverse Osmosis Application. Materials 2016;9:870.

132. Xinlei L, Nilay Keser D, Zhentao W, Kang L. Highly Water-Stable Zirconium Metal-Organic Framework UiO-66 Membranes Supported on Alumina Hollow Fibers for Desalination. J. Am. Chem. Soc. 2015;137:6999-7002.

133. Nightingale ERJ. Phenomenologocal Theory of Ion Solvation. Effective Radii of Hydrated Ions. J. Phys. Chem. 1958;9: 566-567.

134. Fu F, Wang Q. Removal of heavy metal ions from wastewaters: A review. J. Environ. Manage. 2011;92:407-418.

135. Yuan J, Hung W, Zhu H, et al. Fabrication of ZIF-300 membrane and its application for efficient removal of heavy metal ions from wastewater. J. Membr. Sci. 2019;572:20-27.

136. Jamshidifard S, Koushkbaghi S, Hosseini S, et al. Incorporation of UiO-66-NH2 MOF into the PAN/chitosan nanofibers for adsorption and membrane filtration of $\mathrm{Pb}(\mathrm{II}), \mathrm{Cd}(\mathrm{II})$ and $\mathrm{Cr}(\mathrm{VI})$ ions from aqueous solutions. J. Hazard. Mater. 2019;368:10-20.

137. Efome JE, Rana D, Matsuura T, Lan CQ. Experiment and modeling for flux and permeate concentration of heavy metal ion in adsorptive membrane filtration using a metal-organic framework incorporated nanofibrous membrane. Chem. Eng. J. 2018;352:737-744.
138. Yin N, Wang K, Wang L, Li Z. Amino-functionalized MOFs combining ceramic membrane ultrafiltration for $\mathrm{Pb}$ (II) removal. Chem. Eng. J. 2016;306:619-628.

139. Mimura K, Takahashi Y, Takanashi S, Deguchi H. The behaviour of organic matter in hybrid water treatment system. Sep. Purif. Technol. 2019;221:385-392.

140. Jin M, Lin Y, Liao Y, Tan C, Wang R. Development of highly-efficient ZIF-8@PDMS/PVDF nanofibrous composite membrane for phenol removal in aqueous-aqueous membrane extractive process. J. Membr. Sci. 2018;568:121-133.

141. Li Q, Liu Q, Zhao J, et al. High efficient water/ethanol separation by a mixed matrix membrane incorporating MOF filler with high water adsorption capacity. J. Membr. Sci. 2017;544:68-78.

142. Mao H, Zhen H, Ahmad A, Zhang A, Zhao Z. In situ fabrication of MOF nanoparticles in PDMS membrane via interfacial synthesis for enhanced ethanol permselective pervaporation. $J$. Membr. Sci. 2019;573:344-358.

143. Gao B, Jiang Z, Zhao M, et al. Enhanced dehydration performance of hybrid membranes by incorporating lanthanide-based MOFs. J. Membr. Sci. 2018;546:31-40.

144. Sánchez NC, Guzmán-Mar JL, Hinojosa-Reyes L, Palomino GT, Cabello CP. Carbon composite membrane derived from ML-125-NH2 MOF for the enhanced extraction of emerging pollutants. Chemosphere 2019;231:510-517.

145. Kasik A, Lin YS. Organic solvent pervaporation properties of MOF-5 membranes. Sep. Purif. Technol. 2014;121:38-45.

146. Kang C, Lin Y, Huang Y, et al. Synthesis of ZIF-7/chitosan mixed-matrix membranes with improved separation performance of water/ethanol mixtures. J. Membr. Sci. 2013;438: 105-111.

147. Tan Y, Sun Z, Meng H, et al. A new MOFs/polymer hybrid membrane: MIL-68(Al)/PVDF, fabrication and application in high-efficient removal of p-nitrophenol and methylene blue. Sep. Purif. Technol. 2019;215:217-226.

148. Ragab D, Gomaa HG, Sabouni R, Salem M, Ren M, Zhu J. Micropollutants removal from water using microfiltration membrane modified with ZIF-8 metal organic frameworks (MOFs). Chem. Eng. J. 2016;300:273-279. 